\section{SUBJECT SUGARY DRINKS TO SAME RULES AS TOBACCO}

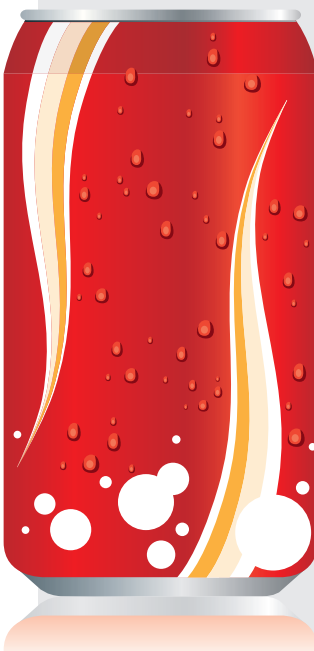

Sugary drinks should be subject to the same advertising and sponsorship rules as tobacco, according to the British Dental Health Foundation (BDHF)

The BDHF believes if major sporting tournaments banned sugary drinks sponsorship similar to the ban on tobacco advertising introduced in 2003 - there would

be a reduction in consumption and an improvement in the health of thousands of people.

Experts suggested more than 3,000 lives could be saved by the tobacco ban, and the BDHF believes a similar ban involving sugary drinks could have benefits for a number of health conditions, notably obesity and oral health.

Sugary drinks are the largest source of sugar for children aged 4-12 and teenagers. This could be why more than one in four (27 per cent) five-year olds ${ }^{1}$, one in three 12 -year olds and nearly half (46 per cent) of 15 -year olds show signs of obvious dental decay $^{2}$.

BDHF trustee Professor Nairn Wilson leads the calls for the government to intervene and treat sugary drinks advertising the same as tobacco.

Professor Wilson said: "Sugar is the biggest health time-bomb we face today.

The dangers of tobacco are very well documented and there has been significant progress made on tobacco advertising in general, and particularly sport.

"When the Indian associate of the British American Tobacco group sponsored the Indian World Cup Cricket team in 1996 with its Wills brand, a survey showed that smoking among Indian teenagers increased five-fold. There was also a marked increase in false perceptions such as 'you become a better cricketer if you smoke Wills' and 'teams with more Wills smokers will fare better's.

"There is every reason to believe this will also apply to sugary drinks. Some of the world's major sports events and sporting names are sponsored and endorsed by sugary drinks brands. Many of them are role models for children, so why would they not follow their idol.

"The same, it is suggested, applies to family-friendly landmarks, such as the Coca-Cola London Eye. Our own research has found that more than four in five people do not agree with their new sponsorship 4 .

"The increase in consumption of sugary drinks is one of the key reasons for dental decay, particularly in children. Proposals such as the introduction of a duty on sugary drinks and brands reducing the amount of sugar in their soft drinks have both been mooted in the last 12 months, and a ban on advertising is another step the government can take to bring about significant health improvements. Levels of obesity, diabetes

and heart problems would undoubtedly decrease if any of these measures were introduced.

"Cutting down on how often you have sugary foods and drinks is one of the BDHF's key messages. The key thing to remember is that

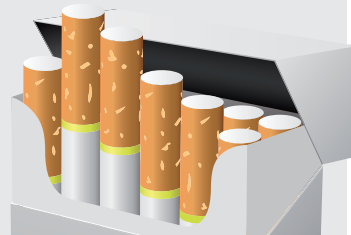
it is how often sugar is consumed, rather than how much sugar, which heightens the risk of tooth decay.

"We call on the health industry to support our calls and lobby government to help safeguard children's oral health now and in the future."

1. hittps://www.gov.uk/government/news/survey-
finds-27-of-5-year-olds-have-tooth-decay
2. Children's Dental Health Survey: England, Wales
and Northern Ireland (2014). Health and Social
Care Information Centre www.hscic.gov.uk/
catalogue/PUB17137/CDHS2013-Executive-
Summary.pdf
3. Vaidya SG, Naik UD, Vaidya JS, Effects of sports
sponsorship by tobacco companies on
children's experimentation with tobacco British
Medical Journal August 1996; 313, 400
4. British Dental Health Foundation (2015), Your Say.
April 2015.

\section{FLASH INTERVIEW}

\section{Angela Shutt \\ Angela is a \\ 33-year-old \\ dental nurse \\ and practice \\ manager at \\ Harrowgate Hill \\ Dental Practice \\ in Darlington, \\ County \\ Durham.}

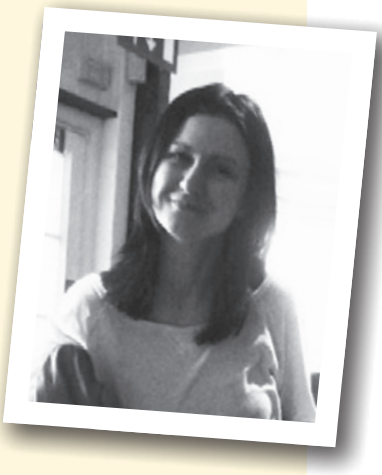

Angela lives with her partner James,

a sales manager, and her children

Chloe (15) and Nathan (6)

\section{How long have you worked in} dentistry? 13 years (qualified 2002)

Why did you choose dentistry for your career? After having extensive ortho work in my teens, I was always fascinated by the role of the dental nurse and everything they had to do.

\section{Do you have any special} responsibilities within your dental practice? I started working at my current practice 2 days a week steadily increasing my hours around my children. I was asked to take over the managerial roll in 2006 and over saw the installation of our CSU. I missed the surgery aspect of the role that I now get to nurse 1 day a week as well as coordinating our weekly domiciliary visits in which I attend with our principal

What do you like best about your job? The satisfaction of seeing someone happy with the service they are provided with.

What is the most challenging part of your job? I have learnt over time you cannot please everyone at once but always try your best to do what is right by people.

What do you like to do outside work? Walking, gardening, eating out and travelling

Tell us a secret. No that would be telling!!

What do you like about BDJ Team? It gives a great insight to all aspects of the dental profession. Great informative articles

What three things could you not live without (besides people)? My dogs, my car and my bed. 